\title{
Preparação para a OBMEP: um relato de sucesso em duas escolas de Araguaína/TO
}

\section{Preparation for OBMEP: a success report in two schools in Araguaína/TO}

\author{
Werley Sales da Silva ${ }^{1}$ \\ Universidade Federal do Norte do Tocantins (UFNT), Araguaína, TO, Brasil \\ https://orcid.org/0000-0003-1307-4554, 9 http://lattes.cnpq.br/6284475603887020
}

Fernanda Vital de Paula²

Universidade Federal do Norte do Tocantins (UFNT), Araguaína, TO, Brasil https://orcid.org/0000-0002-7936-8937, 9 http://lattes.cnpq.br/9279556456110004

\begin{abstract}
Resumo: A Olimpíada Brasileira de Matemática das Escolas Públicas (OBMEP) é um projeto nacional dirigido às Escolas Públicas e Privadas do Brasil, sendo realizada anualmente desde o ano de 2005. Este artigo tem como objetivos: apresentar as contribuições significativas para o ensino-aprendizagem da Matemática por meio do relato de experiência referente a uma ação realizada em duas escolas de Araguaína, TO, visando a preparação dos alunos do Ensino Fundamental para a segunda fase da OBMEP de 2017, 2018 e 2019; e fomentar o interesse docente em refletir sobre a relevância dessa olimpíada no estímulo do interesse dos discentes das escolas públicas, buscando melhorar o desempenho escolar dos alunos. O presente relato aponta que, por meio da OBMEP, os estudantes das referidas escolas passaram a se interessar cada vez mais pela área de Matemática, tendo em vista que a ação possibilitou a ampliação da forma de estudo da disciplina. Essa ação propiciou também o desenvolvimento da autoconfiança dos discentes, de modo que estes puderam notar suas capacidades em participar de uma competição de conhecimento com possibilidades de premiação.
\end{abstract}

Palavras-chave: OBMEP; Matemática; estudantes; aprendizagem; desempenho escolar.

Abstract: The Brazilian Mathematics Olympiad of Public Schools (OBMEP) is a national project aimed at Public and Private Schools in Brazil, being held annually since 2005. The article aim to present the significant contributions to the teaching-learning of Mathematics by reporting an action carried out in two schools in Araguaína, TO, which focused at preparing elementary school students for the second phase of OBMEP in 2017, 2018, and 2019 and also the teacher's interest in reflecting on the relevance of OBMEP in the stimulation of the interest of public school students, seeking to improve students' school performance. The report points out that through OBMEP, students from these schools have become increasingly interested in the field of Mathematics, given that the action made it possible to expand the ways of studying the discipline. The action also fostered the development of students' self-confidence, so that they could notice their abilities to participate in a knowledge competition with possibilities of earning awards.

Keywords: OBMEP; Mathematics; students; learning; school performance.

Data de submissão: 11 de dezembro de 2020.

Data de aprovação: 1 de julho de 2021.

\footnotetext{
${ }^{1}$ Currículo sucinto: Licenciado em Matemática pela Universidade Federal do Tocantins. Contribuição de autoria: Escrita - Primeira Redação, Escrita - Revisão e Edição. Contato: werley sales@hotmail.com.

2 Currículo sucinto: Licenciada em Matemática e mestre em Estatística Aplicada e Biometria pela Universidade Federal de Viçosa, doutora em Estatística pela Universidade Federal de Pernambuco, docente da Universidade Federal do Norte do Tocantins. Contribuição de autoria: Supervisão e análise de dados. Contato: fernandavital@uft.edu.br.
} 


\section{Introdução}

Com o intuito de motivar os alunos a se dedicarem ao estudo de Matemática e identificar talentos na área, no ano de 2005, foi criada a Olimpíada Brasileira de Matemática das Escolas Públicas (OBMEP) (ALVES, 2010). A OBMEP é realizada anualmente pelo Instituto de Matemática Pura e Aplicada (IMPA), com o apoio da Sociedade Brasileira de Matemática (SBM), e promovida com recursos do Ministério da Educação (MEC) e do Ministério da Ciência, Tecnologia, Inovações e Comunicações (MCTIC) (GONÇALVES et al., 2018). Trata-se de um projeto de suma importância, dada sua abrangência nacional, social e educacional, sendo possível observar, conforme os objetivos do projeto, que a OBMEP se propõe como motivadora do aprendizado matemático e beneficiadora da melhora do ensino e aprendizagem da disciplina Matemática nas Escolas.

Diversos pesquisadores e autores confirmam tal motivação e benefício. Conforme afirma Fideles (2014), por exemplo, a OBMEP oferece aos participantes várias oportunidades de aprendizagem, seja na preparação para as provas, durante a própria competição ou após, em um reexame dos problemas junto com o professor, entre outros, colaborando com o desempenho escolar dos alunos no processo de ensino e aprendizagem da Matemática nas Escolas Públicas.

Como problemática, questionou-se: Qual a contribuição da OBMEP na aprendizagem dos estudantes das escolas públicas? A OBMEP tem contribuído com o ensino e aprendizagem da Matemática por meio da preparação para as provas, além de estimular o gosto pelos estudos dos conteúdos da disciplina, proporcionando aos estudantes e aos professores novas descobertas, técnicas e conhecimentos matemáticos, implicando em uma forma crítica e reflexiva.

A elaboração do estudo se justifica em razão de que a OBMEP colabora com a aquisição e ampliação do saber matemático dos estudantes, além de oportunizar a reflexão sobre as contribuições do projeto para a melhoria da qualidade da Educação Básica.

Este artigo tem o objetivo de apresentar as contribuições significativas para o ensinoaprendizagem da Matemática por meio do relato de experiência referente a uma ação realizada em duas escolas de Araguaína, TO, visando a preparação dos alunos do Ensino Fundamental para a segunda fase da OBMEP de 2017, 2018 e 2019, e o interesse docente em refletir sobre a relevância da OBMEP na estimulação do interesse dos discentes das Escolas Públicas, que visa melhorar o desempenho escolar dos alunos.

Para tal, na segunda seção, instiga-se o leitor a uma breve reflexão inicial sobre a OBMEP como instrumento de motivação dos alunos nas Escolas Públicas para estudar Matemática e melhorar o ensino e aprendizagem dos conteúdos da disciplina, baseada em pesquisas bibliográficas e, na terceira seção, apresenta-se o relato da ação realizada em duas escolas de Araguaína, TO, que consistiu na preparação de alunos para a segunda fase da OBMEP. 
A proposta apresentada na pesquisa está inserida na área da Educação Matemática e relacionada, especificamente, ao Ensino da Matemática. A abordagem do tema reflete a possibilidade de investir na OBMEP como estratégia para facilitar a aprendizagem da Matemática através de incentivo e colaboração do professor.

\section{OBMEP}

Em 2005, a OBMEP foi criada pelo Governo Federal. Trata-se de um projeto nacional, promovido com recursos do Ministério da Educação (MEC), realizado pelo Instituto Nacional de Matemática Pura e Aplicada (IMPA) e apoiado pela Sociedade Brasileira de Matemática (SBM).

A OBMEP é realizada anualmente em duas fases, sendo a primeira composta por uma prova objetiva, de caráter eliminatório, com questões de múltipla escolha, e, a segunda, composta por uma prova discursiva. No que se refere ao seu público-alvo, a Olimpíada é destinada a estudantes do $6^{\circ}$ ano do Ensino Fundamental ao $3^{\circ}$ ano do Ensino Médio das Escolas Públicas e Privadas de todo o país, com base em três níveis de classificação, conforme a Tabela 1.

Tabela 1 - Níveis da OBMEP
\begin{tabular}{|c|c|}
\hline Níveis & Anos Escolares \\
\hline 1 & $6^{\circ}$ ano $/ 7^{\circ}$ ano \\
\hline 2 & $8^{\circ}$ ano $/ 9^{\circ}$ ano \\
\hline 3 & Ensino Médio \\
\hline
\end{tabular}

Fonte: OBMEP (2021).

Concorrem a prêmios, os discentes que alcançam o maior número de pontos na segunda fase da edição da OBMEP. Escolas, professores e Secretarias de Educação dos estudantes premiados também são contemplados com medalhas, menções honrosas ou até com vagas no Programa de Iniciação Científica Jr.

Em seu site, a OBMEP (2021) cita que os principais objetivos do projeto são:

1. Estimular e promover o estudo da Matemática;

2. Contribuir para a melhoria da qualidade da Educação Básica, possibilitando que um maior número de alunos brasileiros possa ter acesso a material didático de qualidade;

3. Identificar jovens talentos e incentivar seu ingresso em universidades, nas áreas científicas e tecnológicas;

4. Incentivar o aperfeiçoamento dos professores das escolas públicas, colaborando para a sua valorização profissional;

5. Contribuir para a integração das escolas brasileiras com as universidades públicas, os institutos de pesquisa e com as sociedades científicas;

6. Promover a inclusão social por meio da difusão do conhecimento. 
Com relação a estes objetivos, nota-se que a OBMEP se propõe como motivadora dos discentes em prol do aprendizado matemático, além de proporcionar a melhora do ensino e aprendizagem da Matemática nas escolas públicas. No que se refere à motivação, Fideles (2014) afirma que a Olimpíada de Matemática é para todas as crianças, jovens e educadores que gostam de pensar, adquirir e ampliar o conhecimento, além de estimular o gosto e o prazer pelos estudos da Matemática e por outras ciências, buscando também despertar nos educandos o interesse pelos desafios matemáticos e resoluções de situações problemas, desenvolvendo o raciocínio lógico e a melhora da qualidade do ensino.

Dessa forma, a OBMEP colabora com a motivação dos discentes em estudar e aprender Matemática, facilitando o ensino e aprendizagem e, consequentemente, influenciando o rendimento escolar.

É uma política pública mundialmente reconhecida, uma das maiores iniciativas governamentais voltadas ao processo de ensino-aprendizagem em matemática, visando melhorar a motivação, o interesse e o desempenho dos alunos nas escolas públicas brasileiras (CGEE, 2011, p. 13).

Gadelha et al. (2017) lembram que o processo de ensino e aprendizagem da Matemática no ambiente escolar é temido e cheio de bloqueios. Muitos recursos são propostos para o melhoramento do ensino de Matemática, sendo um deles a OBMEP, que é repleta de prêmios e oportunidades de bolsas em programas conceituados, incentivando tanto a dedicação dos alunos no estudo dos conteúdos da disciplina, como também ajudando os docentes no ensino da mesma, trabalhando questões mais comuns do que possam ser aplicadas no cotidiano.

Algo interessante mencionado por Lima e Ramos (2016) é que as provas da OBMEP abordam os diversos conteúdos da Matemática, principalmente em forma de problemas, e suas questões exigem do participante certa criatividade na sua resolução. A resolução de problemas é uma excelente estratégia de ensino-aprendizagem da Matemática, pois o participante, quando colocado diante de situações e questionamentos, exercita a concentração e o raciocínio lógico, conseguindo compreender o problema, sem a preocupação de utilizar regras padronizadas, o que facilita a aprendizagem do estudante (LIMA; RAMOS, 2016).

Tendo em vista o potencial da OBMEP, verificado nos parágrafos anteriores, nos anos 2017, 2018 e 2019, foi realizada uma ação que visava à preparação dos estudantes de duas Escolas nas quais o primeiro autor deste artigo lecionava em Araguaína, TO, para a segunda fase da OBMEP. Essa preparação teve o intuito de tornar possível a conquista dos prêmios por estes alunos, além de incentivá-los ao estudo de Matemática e colaborar com a aprendizagem e com o rendimento deles.

Vale ressaltar que tais alunos não conheciam a OBMEP e a ideia de apresentar a Olimpíada de Matemática aos mesmos surgiu da busca por metodologias didáticas alternativas, 
inovadoras e criativas a fim de despertar o interesse dos alunos do Ensino Fundamental pela Matemática, colaborando significativamente com o ensino e aprendizagem da disciplina.

Com base na experiência como professor no Ensino Básico ao longo de cinco anos, percebeu-se que os alunos não estavam motivados em aprender os conteúdos de Matemática, pois a classificam como uma disciplina difícil. Então, buscou-se criar um ambiente acolhedor, onde eles se sentissem valorizados, desafiados e estimulados a aprender Matemática de forma prazerosa por meio da resolução de questões da OBMEP, objetivando resultados positivos no contexto qualitativo e quantitativo.

A ação foi centrada na dificuldade de aprendizagem e na desmistificação de que os conteúdos de Matemática são difíceis de compreender. Dessa forma, foram trabalhadas as necessidades individuais dos estudantes que conseguiram adquirir conhecimentos matemáticos, reduziram as dificuldades de aprendizagem, alcançaram um número maior de acertos na prova da OBMEP, além de apresentarem melhor desempenho escolar.

Na próxima seção, relata-se a experiência vivenciada na ação realizada durante o referido triênio e seus resultados.

\section{Relato de experiência}

Nesta seção, o relato referente à experiência vivenciada nos anos 2017, 2018 e 2019 em uma ação que objetivou a preparação de alunos para a segunda fase da OBMEP será descrita. Em termos de organização, o relato foi divido em três subseções: caracterização das escolas e discentes envolvidos; preparação dos estudantes para a segunda fase da OBMEP e resultados obtidos na segunda fase da OBMEP.

\subsection{Caracterização das escolas e alunos envolvidos}

Participaram desta ação os educandos do Ensino Fundamental da Escola Paroquial Sagrado Coração de Jesus e Escola Estadual Professor Alfredo Nasser de Araguaína, TO. A seguir, serão apresentadas algumas informações relevantes acerca destas escolas.

\subsubsection{Escola Paroquial Sagrado Coração de Jesus}

A Escola Paroquial Sagrado Coração de Jesus (EPSCJ) está localizada no centro de Araguaína e atende alunos entre 8 e 14 anos, no período diurno, do $4^{\circ}$ ao $6^{\circ}$ ano do Ensino Fundamental, oriundas de uma comunidade de classe com diferentes níveis socioeconômicos e culturais. Ela busca fortalecer a qualidade do ensino e aprendizagem com ações inclusivas, democráticas, transparentes, solidárias e éticas, valorizando o potencial de cada estudante para que possam desenvolver habilidades e competências específicas, de forma que sejam promovidos para o próximo ano por meio de uma aprendizagem significativa. 
A EPSCJ, conforme seu Projeto Político Pedagógico (PPP), realiza o seu trabalho pedagógico, concentrando esforços na promoção de melhorias dos serviços prestados, buscando diariamente soluções para os grandes problemas educacionais, tais como: evasão, repetência, inclusão e um ensino que favoreça uma aprendizagem qualificada, com inovações que atendam às exigências de uma sociedade moderna e em constantes mudanças.

\subsubsection{Escola Estadual Professor Alfredo Nasser}

A Escola Estadual Professor Alfredo Nasser (EEPAN) atende 738 alunos, do $6^{\circ}$ ao $9^{\circ}$ ano do Ensino Fundamental, entre 10 e 18 anos, nos turnos matutino e vespertino, oriundos de famílias de classe média baixa, onde a maioria dos pais ou responsáveis é de classe média baixa, sendo funcionários públicos ou de comércio, enquanto outros são moradores de chácaras e povoados próximos à cidade de Araguaína.

No ano de 2019, a EEPAN recebeu os estudantes e servidores da EPSCJ, que teve seu convênio encerrado, passando por uma reorganização e adequação. Assim, o atual PPP da EEPAN contempla a história de ambas as escolas. Um dos focos da EEPAN é manter um ambiente acolhedor, organizado, com um trabalho exitoso na questão da disciplina, que busca combater a evasão e preparar os discentes para alcançar um bom desempenho nas avaliações internas e externas, de acordo com o seu PPP.

\subsection{Preparação dos estudantes para a segunda fase da OBMEP}

Ambas as escolas, no triênio em questão, realizaram as inscrições de todos os alunos na primeira fase da OBMEP por acreditarem que a participação deles na Olimpíada de Matemática motivaria o estudo dos conteúdos da disciplina. A ação de preparação dos estudantes para a $2^{\mathrm{a}}$ fase da OBMEP ocorreu na EPSCJ, nos anos 2017 e 2018 e na EEPAN, no ano 2019. As informações quanto ao número de participantes de cada escola nos referidos anos, edições e fases da OBMEP, são apresentados na Tabela 2.

Tabela 2 - Informações referentes ao número de participantes

\begin{tabular}{|c|c|c|c|}
\hline Ano & Escola & Número de alunos ( $1^{a}$ fase) & Número de alunos ( $2^{a}$ fase) \\
\hline 2017 & EPSCJ & 337 & 17 \\
\hline 2018 & EPSCJ & 570 & 29 \\
\hline 2019 & EEPAN & 269 & 20 \\
\hline
\end{tabular}

Fonte: Dados da pesquisa (2020).

A ação sempre ocorreu no segundo semestre do ano letivo, direcionada aos alunos classificados para a segunda fase. As atividades foram desenvolvidas por meio de encontros aos sábados, das $7 \mathrm{~h} 30 \mathrm{~min}$ às $11 \mathrm{~h}$. 
Durante a realização da ação, foram propostas questões discursivas que aguçavam os estudantes a pensar, refletir, questionar e tentar resolvê-los. Além de instigá-los, buscou-se mostrar aos estudantes a importância e a influência da Matemática na vida cotidiana, estabelecendo uma associação entre os conhecimentos da disciplina e a realidade deles. As questões estudadas eram de edições anteriores da segunda fase da OBMEP, que foram exibidas no por meio de projetor multimídia do Laboratório de Informática das duas escolas, instigando os educandos a resolvê-las, propiciando a interação e o debate sobre a melhor estratégia para resolver o problema proposto.

As questões selecionadas exigiam raciocínios simples e complexos, proporcionando uma base sólida de conhecimentos matemáticos aos estudantes para que enfrentassem os demais participantes da OBMEP com mais preparo, além de melhorar o rendimento escolar ao incentiválos ao estudo de Matemática. A prova da segunda fase da Olimpíada de Matemática, por ser discursiva, exige um bom nível de conhecimento e raciocínio que é essencial para se obter êxito. Neste sentido,

A proposta de resolver questões de provas anteriores vem para desmistificar a ideia da prova da OBMEP ser muito difícil. Desta maneira, trilhamos um caminho em que o aluno constrói hipóteses, tira suas próprias conclusões e interage com colegas e professores (BORTOLETTI; ZANCANARO, 2017, p. 4).

A prova da segunda fase da OBMEP consiste de uma avaliação com seis questões discursivas, com itens de "A" a "D", onde os alunos têm que apresentar os cálculos, bem como o raciocínio empregado na resolução dos problemas. Salienta-se que a ação foi o primeiro contato dos discentes com as questões no formato da segunda etapa.

Algumas recomendações foram feitas aos educandos para que se preparassem para a Olímpiada de Matemática, tais como: criar uma rotina de estudos; consultar as edições do Banco de Questões da OBMEP; pesquisar materiais de várias fontes; realizar simulados; assistir videoaulas nos canais da OBMEP; frequentar cursos preparatórios para olimpíadas; estudar e resolver provas de anos anteriores; resolver as questões de forma estratégica, usando lógica, raciocínio e criatividade; investir tempo na leitura das questões e na interpretação dos textos, para compreender os enunciados a fim de resolvê-los adequadamente; criar grupo de estudos com colegas de escola; dedicar aos estudos e confiar na capacidade de resolver as questões.

Sempre foi enfatizado aos estudantes que as estratégias adotadas para solução do item "A" de cada questão é um pré-requisito para solucionar as letras seguintes, conforme as resoluções das questões disponibilizadas pela própria OBMEP após aplicação da prova. Para verificação deste fato, a seguir, são destacadas três questões da segunda fase da OBMEP, nível I, referentes aos anos de 2017, 2018 e 2019. 
Questão 1: (Provas e Soluções da OBMEP 2017: $2^{\circ}$ fase, nível 1, problema 3). André, Bernardo e Carlos retiraram, respectivamente, 1/2, 2/7 e 1/14 do total de doces de um pacote (Figura 1).

Figura 1 - Questão 3 da prova da $2^{\mathrm{a}}$ fase da OBMEP 2017. Pacote de Doces.

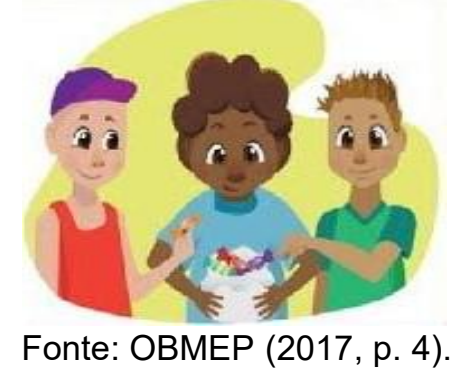

a) Quem retirou o menor número de doces?

b) A quantidade de doces que restou no pacote corresponde a que fração do total?

c) André deu 15 doces a Carlos e ficou com o mesmo número de doces que Bernardo. Quantos doces havia inicialmente no pacote?

Questão 2: (Provas e Soluções da OBMEP 2018: $2^{\circ}$ fase, nível 1, problema 2). Joãozinho comprou um álbum em que as figurinhas (Figura 2) numeradas devem ser coladas em ordem crescente, começando na página 2 e terminando na página 61. Nas páginas pares, devem ser coladas 5 figurinhas, e, nas ímpares, 6 figurinhas.

Figura 2 - Questão 2 da prova da $2^{\mathrm{a}}$ fase da OBMEP 2018. Álbum de Figurinhas.

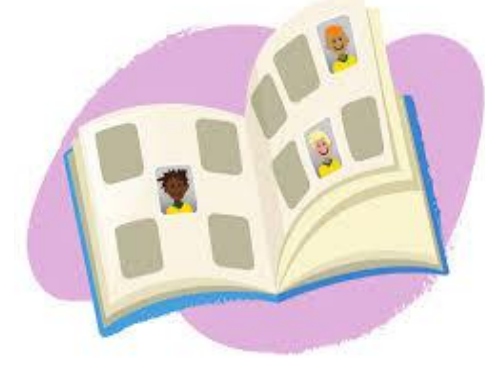

Fonte: OBMEP (2018, p. 3).

a) No total, quantas figurinhas devem ser coladas no álbum?

b) Em qual página deve ser colada a figurinha de número 196?

c) Para completar seu álbum, Joãozinho comprou muitos pacotes de figurinhas. Após colar a última figurinha que faltava, o número de figurinhas repetidas era oito vezes o número de figurinhas coladas. Se o álbum custou 20 reais e cada pacote com 5 figurinhas custou 2 reais, quanto Joãozinho gastou para ter seu álbum completo? 
Questão 3: (Provas e Soluções da OBMEP 2019: $2^{\circ}$ fase, nível 1, problema 2). Roberta tem duas cartelas, uma com os números de 1 a 15 e outra com os números de 16 a 30 . Ela escolhe um número de cada cartela e calcula a soma deles. Veja a Figura 3 que mostra as duas cartelas.

Figura 3 - Questão 2 da prova da $2^{\mathrm{a}}$ fase da OBMEP 2019. Cartelas de Roberta.

\begin{tabular}{|c|c|c|c|c|}
\hline 1 & 2 & 3 & 4 & 5 \\
\hline 6 & 7 & 8 & 9 & 10 \\
\hline 11 & 12 & 13 & 14 & 15 \\
\hline
\end{tabular}

\begin{tabular}{|l|l|l|l|l|}
\hline 16 & 17 & 18 & 19 & 20 \\
\hline 21 & 22 & 23 & 24 & 25 \\
\hline 26 & 27 & 28 & 29 & 30 \\
\hline
\end{tabular}

Fonte: OBMEP (2019, p. 3).

a) Quais são as escolhas possíveis para Roberta obter a soma 18 ?

b) Se Roberta fizer todas as escolhas possíveis, quantos resultados diferentes ela poderá obter?

c) Se Roberta fizer todas as escolhas possíveis, qual é o resultado que aparecerá mais vezes? Por quê?

Salienta-se que as questões explanadas na ação estão alinhadas com as competências e habilidades propostas na Base Nacional Comum Curricular (BNCC), que estão basicamente associadas ao raciocinar, representar, comunicar e argumentar, havendo o letramento matemático, favorecendo a formulação e a resolução de problemas, levando os estudantes para além dos cálculos. Sabe-se que na Matemática a BNCC propõe cinco unidades temáticas, que orientam as habilidades as quais deverão ser formuladas e desenvolvidas no Ensino Fundamental: números, álgebra, geometria, grandezas e medidas e probabilidade e estatística.

Diante das três questões da segunda fase da OBMEP, nível 1, referentes aos anos de 2017, 2018 e 2019, observou-se que a maior vantagem da participação dos discentes na OBMEP é a interdisciplinaridade entre a Matemática e a Língua Portuguesa, pois a leitura e a interpretação são fundamentais para entender bem os enunciados e resolvê-los corretamente, além de colaborar com a melhora do rendimento escolar na área da Matemática.

Nos encontros, observou-se que nem todos os discentes conseguiam resolver as questões, porém, sempre se valorizou a reflexão dos alunos acerca de caminhos estratégicos para a resolução de problemas, a criação de familiaridade dos alunos com o modelo de prova da segunda fase da OBMEP, bem como o aprimoramento da visão dos alunos em relação à Matemática, preparando-os para exames futuros e para situações do cotidiano que envolvessem a disciplina.

Após a tentativa individual de resolução das questões propostas, eram realizadas rodas de conversas, com discussões e troca de conhecimentos entre os estudantes que analisavam de 
forma conjunta as resoluções dos problemas, assim como as estratégias e métodos utilizados. Essa troca gerava a percepção importante de que existem várias soluções distintas para uma mesma questão. Em seguida, as questões eram resolvidas no quadro branco pelo professor, esclarecendo as dúvidas dos alunos e acatando ideias advindas dos mesmos para resolução das questões.

Salienta-se que a percepção dos discentes participantes da ação nas Escolas a respeito da OBMEP não corresponde apenas à premiação ou competição, mas é visto como algo que contribui para a sua formação, com possibilidades e oportunidades de crescimento no aspecto pessoal e como futuro profissional.

De modo geral, os encontros foram significativos mediante a oportunidade proporcionada aos alunos de resolver exercícios e se prepararem para a segunda fase da OBMEP, melhorando o raciocínio e habilidade deles em Matemática para a vida e para avaliações futuras como o Exame Nacional do Ensino Médio (ENEM) e Sistema de Avaliação da Educação do Estado do Tocantins (SAETO).

\subsection{Desempenho dos alunos na segunda fase da OBMEP}

Quanto ao desempenho dos estudantes participantes da ação e classificados para a segunda fase da OBMEP, pode-se dizer que dos 17 (dezessete) estudantes de 2017, 2 (dois) conquistaram medalhas de bronze e 2 (dois) foram contemplados com menção honrosa.

A Figura 4 exibe um gráfico que representa o desempenho e conquista dos prêmios dos alunos da EPSCJ, comparadamente com as demais escolas de Araguaína, TO, que também tiveram discentes do nível 1, classificados para a segunda fase da OBMEP. As demais escolas são: Escola Estadual Deputado Federal José Alves de Assis (EEDFJAA), CAIC Jorge Humberto Carmargo (CAICJHC), Colégio Estadual Professora Silvandira Sousa Lima (CEPSSL) e Escola Paroquial Luiz Augusto (EPLA).

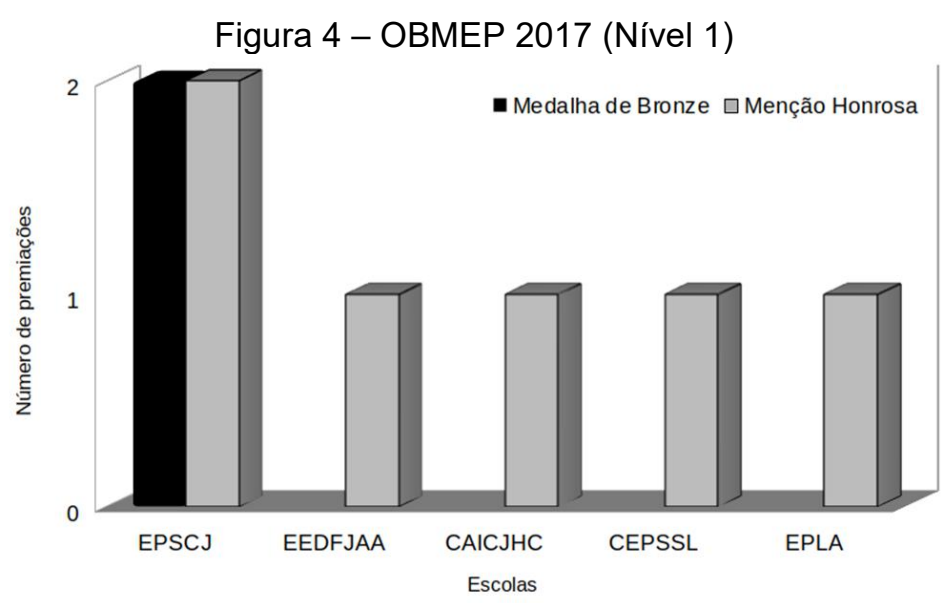

Fonte: Dados da pesquisa (2020). 
É possível observar o destaque da EPSCJ em relação às demais escolas, no que se refere ao número de premiações, sendo a única instituição escolar a ser premiada com medalha de bronze. Em relação ao número de premiações, a EPSCJ conquistou 50\% do total.

Já na $14^{a}$ edição da OBMEP, com a repercussão do sucesso da EPSCJ na edição anterior, ocorreu um aumento significativo no número de inscrições dos estudantes, comparado à edição anterior, havendo também um aumento do número de classificados para a segunda fase, conforme informações apresentadas na Tabela 2, dos quais 5 (cinco) conquistaram medalhas de bronze e 5 (cinco) receberam menção honrosa. Tal fato evidencia que a OBMEP pode influenciar os alunos em querer participar da Olimpíada, e, consequentemente, permite a aquisição e ampliação do conhecimento matemático dos participantes.

A Figura 5, exibe a comparação do número de premiações com as demais Escolas de Araguaína - TO. Aqui, as demais escolas com alunos premiados, além da CAICJHC, são: Escola Estadual Aldofo Bezerra de Menezes (EEABM), Colégio Estadual Professora Silvandira Sousa Lima (CEPSSL) e Escola Estadual João Guilherme Leite Kunze (EEJGLK).

Figura 5 - OBMEP 2018 (Nível 1)

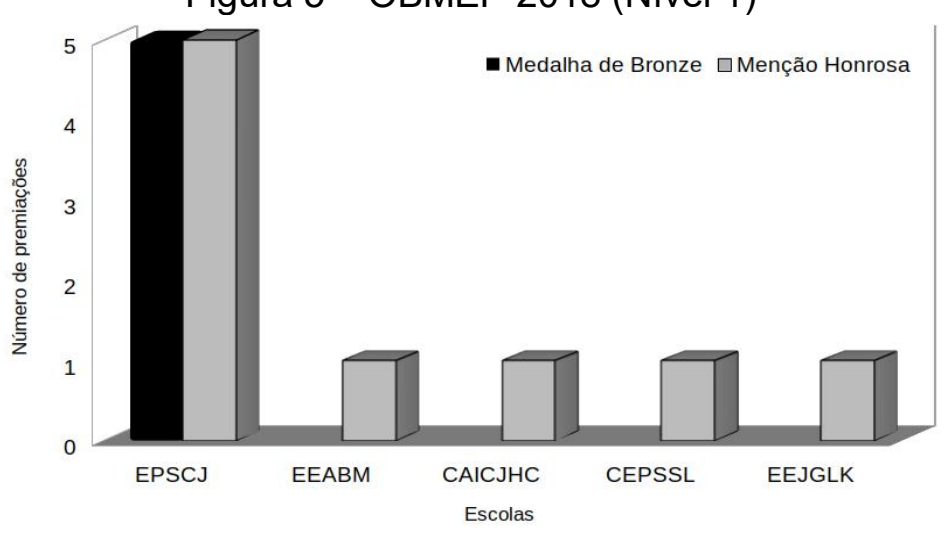

Fonte: Dados da pesquisa (2020).

Nesta edição, o destaque da EPSCJ é ainda maior em relação às demais Escolas, no que se refere ao número de premiações, sendo novamente, a única instituição escolar a ser premiada com medalha de bronze. Sobre o número de premiações, a EPSCJ conquistou $71,4 \%$ do total. $O$ número de premiações dos estudantes da EPSCJ evidenciou o sucesso da ação, adicionada à dedicação do professor no desenvolvimento de seu trabalho em sala de aula. Notou-se também que os alunos melhoraram o desempenho escolar, pois o estudo dos materiais da OBMEP contribuiu fortemente com o enriquecimento do saber na disciplina de Matemática.

Destaca-se também o empenho do professor, que foi responsável pela execução da ação de investir em novas metodologias de ensino, com o intuito de estimular os alunos a estudar os conteúdos de Matemática de forma alternativa, criativa e divertida, enquanto se preparavam para as provas da OBMEP. A dedicação do docente foi reconhecida por meio das premiações 
conquistadas, onde recebeu um livro de apoio à formação Matemática e um diploma de homenagem. Ressalta-se que o professor foi o único homenageado pela OBMEM em Araguaína, TO, nos referidos anos.

A EPSCJ não participou da $15^{a}$ edição da OBMEP, enquanto a EEPAN teve sua primeira participação na Olimpíada, tendo conseguido 2 (duas) medalhas de bronze e 5 (cinco) menções honrosas.

Os resultados são representados na Figura 6. As demais escolas premiadas, além da CAICJHC e EPLA são as seguintes: Escola Estadual Modelo (EEM), Colégio Estadual Marechal Rondon (CEMR), Colégio Estadual Jardim Paulista (CEJP) e Escola Estadual Norte Goiano (EENG).

Figura 6 - OBMEP 2018 (Nível 1)

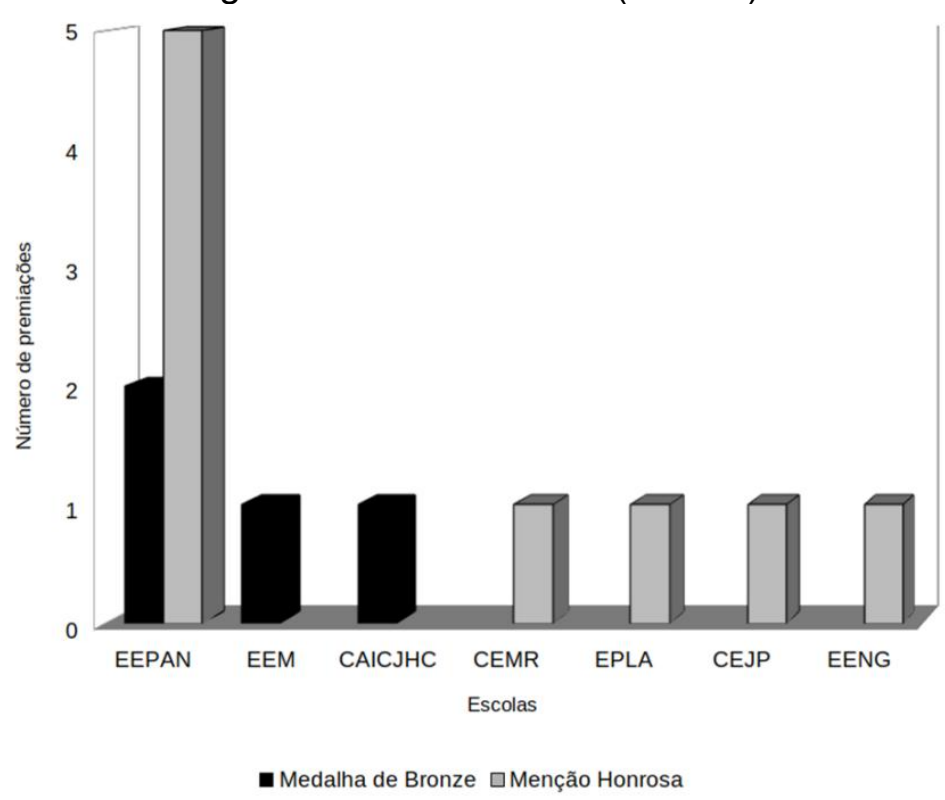

Fonte: Dados da pesquisa (2020).

Nesta edição, o destaque da EEPAN é relevante quando comparado às demais escolas, no que se refere ao número de premiações. A escola recebeu o maior número de medalhas de bronze e o maior número de menções honrosas. Em relação ao número de premiações, a EEPAN conquistou $53,8 \%$ do total. Mais uma vez, o número de premiações dos alunos da EPSCJ evidencia o sucesso da ação realizada.

De modo geral, a execução e os resultados alcançados na ação foram satisfatórios, pois a OBMEP é um instrumento que estimula não só o preparo dos alunos para as competições, conquistas de premiações, mas também estimulou o estudo e aprendizagem prazerosa dos conteúdos da Matemática. Na ação, sempre foi destacado aos discentes a importância da disciplina na sociedade e na formação integral do cidadão, além de estimular o pensamento lógico, autônomo, reflexivo, crítico, ofertando possibilidades e oportunidades. 


\section{Considerações finais}

A OBMEP tem contribuído significativamente com o processo de ensino e aprendizagem dos conteúdos da disciplina de Matemática, que aliada com o trabalho do professor na sala de aula, tem sido considerada uma grande incentivadora dos alunos de escolas públicas nesse processo. Tal fato foi evidenciado pelas reflexões apresentadas sobre a OBMEP e pelos resultados positivos da ação realizada nas duas escolas.

Neste relato de experiência, é possível observar a importância da OBMEP para a Matemática ao estimular o estudo da disciplina por meio da resolução de problemas que despertam a curiosidade dos estudantes, proporcionando a aquisição e ampliação do saber matemático, além de colaborar com o bom rendimento escolar do educando.

Vale mencionar que a percepção dos estudantes de ambas as escolas acerca da OBMEP, não corresponde apenas à premiação ou competição, mas como contribuição às suas formações, gerando possibilidades e oportunidades. Representar as escolas na OBMEP nos anos de 2017, 2018 e 2019, fez com que os estudantes fossem estimulados a estudar os conteúdos da Matemática de forma alternativa e prazerosa. A OBMEP propiciou também o desenvolvimento da autoconfiança dos estudantes, onde eles perceberam que são capazes de participar de uma competição de conhecimento com possibilidades de premiação.

Conclui-se que a OBMEP é uma ferramenta eficaz que colabora com o ensino público de qualidade, além de incentivar os alunos a estudar de forma prazerosa os conteúdos da disciplina e consequentemente melhorar o desempenho escolar dos discentes.

\section{REFERÊNCIAS}

ALVES, W. J. S. O Impacto da Olimpíada de Matemática em Alunos da Escola Pública. Orientadora: Maria José Ferreira da Silva. 2010. 30 f. Dissertação (Mestrado profissional em Ensino de Matemática) - Programa de Estudos Pós-Graduados em Educação Matemática, Pontifícia Universidade Católica de São Paulo, São Paulo, 2010. Disponível em: https://tede2.pucsp.br/handle/handle/10840. Acesso em: 1 set. 2021.

BORTOLETTI, A. A.; ZANCANARO, R. A OBMEP contribuindo para o ensino de Matemática: nossa primeira participação. In: CONGRESSO INTERNACIONAL DE ENSINO DA MATEMÁTICA, 7., 2017, Canoas, RS. Anais [...]. Canoas: ULBRA, 2017. p. 1-10. Disponível em: http://www.conferencias.ulbra.br/index.php/ciem/vii/paper/viewFile/6595/4221. Acesso em: 1 set. 2021.

CGEE. Centro de Gestão e Estudos Estratégicos. Avaliação do impacto da Olimpíada Brasileira de Matemática nas escolas públicas - OBMEP 2010. Brasília: Centro de Gestão e Estudos Estratégicos, 2011. Disponível em: http://server22.obmep.org.br:8080/media/servicos/recursos/251395.o. Acesso em: 15 set. 2021.

FIDELES, E. C. A OBMEP sob uma perspectiva de resolução de problemas. Orientador: Kellcio Oliveira Araújo. 2014. 57 f. Dissertação (Mestrado Profissional em Matemática) - Programa de Mestrado Profissional em Matemática em Rede Nacional, Universidade de Brasília, Brasília, 
2014. Disponível em:

https://repositorio.unb.br/bitstream/10482/17049/1/2014 EduardoCordeiroFideles.pdf. Acesso em: 1 set. 2021.

GADELHA, R. de M.; SILVA, E. E. V. da; SILVA, E. V. da; SILVA, S. da; SILVA, V. V. da. Desempenho de escolas públicas na Olimpíada Brasileira de Matemática na cidade de Paulista, Paraíba. Revista Brasileira de Educação e Saúde, Pombal, PB, v. 7, n. 3, p. 95-99, 1 jul. 2017. DOI: https://doi.org/10.18378/rebes.v7i3.4783.

GONÇALVES, E. N.; SILVA, A.; CLAUDINO, D. D.; PEREIRA, V. A. S.; ALVES, V. S. A OBMEP como instrumento de motivação para os alunos dos $6^{\circ}$ e $7^{\circ}$ anos do Ensino Fundamental. In: CONGRESSO NACIONAL DE EDUCAÇÃO, 6., 2018, Alagoas. Anais [...]. Maceió: CONEDU, 2018. p.1-6. Disponível em:

https://www.editorarealize.com.br/editora/anais/conedu/2019/TRABALHO EV127 MD4 SA13 ID 11293 20082019232151.pdf. Acesso em: 1 set. 2021.

LIMA, V. M. R; RAMOS, A. F. A Olimpíada Brasileira de Matemática sob a ótica dos docentes das escolas públicas de Água Branca-PI. Somma, Teresina, PI, v. 2, n. 1, p. 6-21, jan./jun. 2016.

Disponível em: http://ojs.ifpi.edu.br/revistas/index.php/somma/article/view/71. Acesso em: 1 set. 2021.

OBMEP. Olimpíada Brasileira de Matemática das Escolas Públicas. Provas e Soluções. 2017. Rio de Janeiro: IMPA. Disponível em: http://www.obmep.org.br/provas.htm. Acesso em: 4 dez. 2020.

OBMEP. Olimpíada Brasileira de Matemática das Escolas Públicas. Provas e Soluções. 2018. Rio de Janeiro: IMPA. Disponível em: http://www.obmep.org.br/provas.htm. Acesso em: 4 dez. 2020.

OBMEP. Olimpíada Brasileira de Matemática das Escolas Públicas. Provas e Soluções. 2019. Rio de Janeiro: IMPA. Disponível em: http://www.obmep.org.br/provas.htm. Acesso em: 4 dez. 2020.

OBMEP. Olimpíada Brasileira de Matemática das Escolas Públicas. Regulamento. Rio de Janeiro: IMPA. Disponível em: http://www.obmep.org.br/regulamento.htm. Acesso em: 1 set. 2021. 